Article

\title{
Additionality Effects of Rebate Programs in the Residential Water Sector: Indoor vs. Outdoor
}

\author{
María Pérez-Urdiales *(D) and Kenneth A. Baerenklau
}

School of Public Policy, University of California Riverside, Riverside, CA 92521, USA; ken.baerenklau@ucr.edu

* Correspondence: maria.perezurdiales@ucr.edu; Tel.: +1-(951)-827-2628

Received: 2 May 2019; Accepted: 31 May 2019; Published: 4 June 2019

check for updates

\begin{abstract}
Rebate programs are often used in the residential water sector to alleviate market failures that may hamper the adoption of water-efficient technologies. In this paper, we examine whether several rebate programs stimulate or crowd out private investment in indoor and outdoor technologies. To do so, we use a panel of household-level data from a water district in Southern California for the period 2014-2015. Our results indicate that, while all the rebate programs considered in the analysis increase private investment in water-efficient technologies, only outdoor rebate programs generate further private investment in other outdoor technologies.
\end{abstract}

Keywords: residential water demand; rebate programs; additionality; average treatment effect

JEL Classification: Q20; Q25; Q28

\section{Introduction}

As more frequent and severe droughts are expected to affect many parts of the world, increasing efforts are being made to ensure water availability. Innovation in water-efficient technologies (such as low-flow toilets, high-efficiency washing machines and weather-based irrigation controllers) has rapidly increased in recent years, as can be inferred from the rise in the number of patents in this sector. The number of patents granted worldwide for demand-side (i.e., water conservation) technologies has increased by $150.3 \%$ from 2005 to 2014 , whereas the total number of patents worldwide increased by only $102.14 \%$ during the same period [1].

However, the increase in the number of patents alone is not sufficient to generate water savings from a new technology. As noted by [2], water savings result from a three step process. First, a new technical idea needs to be developed (invention); then, this idea needs to be transformed into a product (innovation); last, the product must become widely adopted (diffusion). Similar to the case of environmental pollution studied by [3], there exist market failures associated with water use that interact with market failures related to technological innovation and diffusion that may hamper the adoption of new technologies. Regarding the former, consider that most water is not supplied by a competitive market, thus consumers do not face the full opportunity cost of their water use. Instead, they typically face the out-of-pocket cost of delivering water. This means water is under-priced, and water-efficient technologies are uneconomical compared to their less-efficient alternatives, and thus consumption is inefficiently high. Practical impacts of this include over-extraction of ground and surface water supplies and associated environmental degradation. Regarding the latter type of market failure, consider that innovation and diffusion of new technologies are characterized by uncertainty [3]. Greater uncertainty about new technologies compared to their more established alternatives creates a disincentive for adoption, even if consumers would be better-off selecting the new technology. In this context, public policies such as rebate programs (i.e., technology subsidies for consumers) are commonly used to foster the adoption of new water-efficient technologies. 
One of the main concerns regarding the use of rebates to promote technology adoption is whether such incentives lead to additional technological adoption that would not have been achieved in the absence of the rebate program. This is known in the literature as the "additionality" question. As [4] argue for the case of electricity conservation programs, many participants in rebate programs may be non-additional, instead obtaining a rebate (subsidy) merely to substitute public funding for private investment in the subsidized technology. As a consequence, several studies in the energy and water economics literature examine whether rebate programs effectively promote greater adoption of the subsidized technology. Among these, ref. [5] use a regression discontinuity analysis to examine additionality of energy-efficiency subsidies, focusing on air conditioners and refrigerators [6] estimate a difference-in-difference model to measure the reduction in water use generated by a rebate program for the adoption of high-efficiency toilets. Ref. [7] analyze data from three randomized field experiments to understand whether social comparisons act as a water conservation tool, in particular when interacted with rebate programs. While most papers measuring additionality analyze the effect of rebate programs in terms of reductions in energy and water consumption, as far as we are aware, no study considers whether participation in rebate programs may affect private investments in other efficient technologies.

In this paper, we take a different approach to analyze the effectiveness of rebate programs by adapting a common method in the $R \& D$ literature. In particular, we compare the level of investment in water-efficient technologies between rebate program participants and non-participants, but we do not limit our focus to the subsidized technology. Rather, we consider the extent to which a rebate for a water-efficient technology creates additional private investment in water efficiency more generally. This approach allows us to tackle two research questions. The first is similar to the additionality question, but broader: does a technology rebate lead to private investments in water-efficient technologies beyond what would have been achieved in the absence of the rebate program? That is, we test for a "crowding-out" effect. The second question is: does a technology rebate lead to private investment in unsubsidized water-efficient technologies specifically? We refer to this as an "acceleration effect". One of the main advantages of our approach compared to previous papers in the water economics literature is that it allows us to disentangle this indirect investment effect.

To examine these two questions, we use data from the Moulton Niguel water district in Southern California. These data are particularly useful because multiple rebate programs for the adoption of both indoor and outdoor water-efficient technologies were offered in recent years to strengthen local drought resilience. However, one of the challenges in using this data is that we observe the year but not the month of adoption for the unsubsidized water-efficient technologies. As a consequence, it is not possible to directly measure rebate-induced water savings. Instead, we focus on measuring investment in water-efficient technologies, and use these results combined with water saving estimates from the literature to construct policy implications.

Our results indicate that each of the four rebates considered in the analysis achieve investment in water-efficient technologies that would not have occurred in the absence of the rebate. Moreover, we find that rebates for outdoor water-efficient technologies also achieve additional private investment in other unsubsidized technologies, but rebates for indoor technologies do not. Considering that outdoor technologies also have larger water conservation potential and are generally in earlier adoption stages, policymakers should focus on these technologies to foster water conservation.

\section{Motivation for Water Conservation Rebate Programs}

Water conservation technologies may generate positive externalities (such as enhanced availability of water for environmental or emergency uses, or improved information about the effectiveness of new technologies) that typically are not internalized by the technology adopters. Therefore, the level of privately financed household water conservation may be lower than socially desired, which provides economic motivation for policies that promote greater private investment. In order to encourage 
greater investment in water conservation technologies, water districts often use rebate programs that reduce the price of these technologies and thus increase demand. However, households may apply for rebate programs merely to finance investment in water conservation technologies that they would adopt anyway in the absence of the incentive. That is, households may substitute public for private investment. On the basis of this reasoning we can hypothesize the following:

Hypothesis 1. There exists total crowding-out if we observe a complete substitution of public for private investment.

Under total crowding-out, the level of investment in water-efficient technologies is not significantly larger for households participating in the rebate program. One cause of total crowding-out would be if the average household decides to invest in a certain level of water-efficient technologies separately from the decision participate in the rebate program.

Hypothesis 2. Similarly, there exists partial crowding-out when we observe a partial substitution of public for private investment.

This hypothesis implies that the level of investment in water-efficient technologies among households participating in the rebate program is significantly higher than it would be in the absence of the rebate, but lower than the level of subsidies granted. That is, while there is additional investment in water-efficient technologies, it is less than the amount of rebates offered. In this case, the level of investment in water-efficient technologies excluding the subsidized technology is smaller than the level of investment in water-efficient technologies in the absence of the rebate.

Hypothesis 3. There is no acceleration when participant households do not adopt other unsubsidized water-efficient technologies jointly with the subsidized technology.

Under this hypothesis, the rebate program may achieve additional adoption of the subsidized technology, but no further adoption of other water-efficient technologies will be achieved.

\section{Method}

The hypotheses defined above were tested separately for each of the rebates considered. In order to test these hypotheses, and following [8,9], we first defined two measures of investment in technologies for each rebate: the level of investment in water-efficient technologies adopted during the period of observation including the subsidized technology (Tot_WT), and the level of investment in water-efficient technologies adopted during the observation period excluding the subsidized technology (NoSub_WT). To estimate the effect of the rebate programs on these measures, we conduct a treatment analysis that allows us to understand the extent households have adopted water conservation technologies, on average, due to receiving a rebate. We focus explicitly on rebate program participants and we estimate the average treatment effect on the treated (ATET). As noted by [10], ATET is defined as the difference between the expected outcome (investment in water-efficient technologies) with and without treatment (a rebate) for those participating in the treatment (rebate program participants). Using the measure Tot_WT, ATET is defined as:

$$
\tau^{A T E T}=E\left(T o t_{-} W T_{1 i} \mid R=1\right)-E\left(T_{0} t_{-} W T_{0 i} \mid R=1\right),
$$

where $\tau^{A T E T}$ is the average treatment effect on the treated, and $T o t_{-} W T_{1 i}$ and $T o t_{-} W T_{0 i}$ indicate the total levels of investment in water conservation technologies in the case of treatment and the counter factual situation of no treatment, respectively. $R$ indicates the treatment status with $R=1$ indicating that the household receives a rebate. 
Similarly, we used the measure NoSub_WT to estimate another average treatment effect on the treated $\alpha^{A T E T}$ defined as:

$$
\alpha^{A T E T}=E\left(N o S u b \_W T_{1 i} \mid R=1\right)-E\left(N o S u b_{-} W T_{0 i} \mid R=1\right),
$$

where NoSub_WT $T_{1 i}$ and NoSub_WT $T_{0 i}$ represent analogous levels of investment for the situations of treatment and no treatment, respectively.

Of course, $T_{0} t_{-} W T_{0 i}$ and NoSub_WT $T_{0 i}$ were not observed for rebate program participants, as they describe the hypothetical outcomes associated with not receiving a rebate for those households who participated in the rebate program. To address this challenge, we could use non-participants as control group if $E\left(T_{o} t_{-} W T_{0 i} \mid R=1\right)=E\left(T_{0} t_{-} W T_{0 i} \mid R=0\right)$ and $E\left(N_{o} S_{u} b_{-} W T_{0 i} \mid R=1\right)=$ $E\left(N_{o S u b} W T_{0 i} \mid R=0\right)$. However, because rebate participants were not randomly assigned, these conditions likely did not hold, and thus using non-participants as a control group would have yielded biased results. In order to control for this problem, we followed the approach by [8,9], and implement a matching technique to estimate the average treatment effect on the treated. Matching involved pairing households participating in a rebate program with non-participating comparison households that are similar in terms of observable characteristics. As discussed by [11], matching is straightforward if we only observe a small number of characteristics. However, when participant and non-participant households may differ across a large number of variables, matching becomes more difficult.

In this context, propensity score matching can provide a weighting scheme to estimate an unbiased treatment effect. The propensity score, i.e., the probability of receiving a rebate $p(x)$ conditional on some pre-treatment characteristics $x$ was defined as [12]:

$$
p(x) \equiv \operatorname{Pr}(R=1 \mid x) .
$$

As noted by [11], any standard probability model, such as probit, can be used because the objective of the propensity score is to reduce the dimensionality of the observable characteristics, and there are no behavioral assumptions attached to the model. Moreover, ref. [10] indicate that the choice between logit and probit is not critical, as these models yield similar results. In this paper, the propensity score is estimated using a probit model. Regarding the matching algorithm, we used the nearest-neighbor matching, as it is the most straightforward algorithm [10]. This involves matching a household participating in a rebate program with a non-participant household that is closest in terms of its propensity score. When using the nearest-neighbor matching, one has to decide how many non-participant households should be chosen for each household participating in a rebate program. In this paper, we follow the recommendation of [13] and we select one non-participant household for each participant, as this choice tends to minimize bias. (The reader is referred to [12] for more details about the matching algorithm.)

After matching households based on their propensity score, the second step implies computing the ATET as in Equations (1) and (2):

$$
\begin{gathered}
\tau^{A T E T}=E\left(T o t_{-} W T_{1 i} \mid R=1, p(x)\right)-E\left(T o t_{-} W T_{0 i} \mid R=0, p(x)\right) \\
\alpha^{A T E T}=E\left(N o S u b_{-} W T_{1 i} \mid R=1, p(x)\right)-E\left(N o S u b \_W T_{0 i} \mid R=0, p(x)\right) .
\end{gathered}
$$

Equations (4) and (5) can be estimated as follows:

$$
\begin{gathered}
\tau^{A T E T}=\frac{1}{N^{T}} \sum_{i \in T}\left[T o t_{-} W T_{i}^{T}-\sum_{j \in C(i)} w_{i j} T o t_{-} W T_{j}^{C}\right] \\
\alpha^{A T E T}=\frac{1}{N^{T}} \sum_{i \in T}\left[N o S u b_{-} W T_{i}^{T}-\sum_{j \in C(i)} w_{i j} N o S u b_{-} W T_{j}^{C}\right],
\end{gathered}
$$


where $N^{T}$ is the number of households participating in a rebate program, $C(i)$ is the set of non-participating households matched to participant household $i$ and $w_{i j}$ is the weight of non-participant household $j$ (with $\sum_{j \in C(i)} w_{i j}=1$ ).

Once we obtained $\tau^{A T E T}$ and $\alpha^{A T E T}$, we can test the hypotheses discussed in Section 2. We can reject the null hypothesis of total crowding-out if we find evidence that $\tau^{A T E T}>0$, i.e., the total level of investment in water-efficient technologies is significantly larger for rebate participants. Moreover, $\alpha^{A T E T}$ allowed us to simultaneously test Hypotheses 2 and 3. First, if $\alpha^{A T E T} \geq 0$, the level of investment in unsubsidized devices among rebate program participants was not less than the level of investment among non-participants, indicating that there is no partial substitution of public for private investment. Therefore, we can reject the null hypothesis of partial crowding-out. Second, if $\alpha^{A T E T}>0$, rebate participants showed a larger level of investment in unsubsidized technologies than the level of investment among non-participants. In this case, we can reject the null hypothesis of no acceleration effect.

To further explore the nature of additionality effects, we also disaggregated our data into technologies that were used indoors vs. those that were used outdoors, and considered each subset separately. That is, we conducted the same tests using the investments in indoor and outdoor water-efficient technologies (Indoor_WT and Outdoor_WT, respectively), and the investments in indoor and outdoor water-efficient technologies excluding the subsidized technology (IndoorNoSub_WT and OutdoorNoSub_WT).

\section{Data}

We used a database of single-family residential households in Southern California served by the Moulton Niguel water district (MNWD). This water district provides water, recycled water and waste-water treatment services to the Orange County cities of Aliso Viejo, Laguna Niguel, Laguna Hills, Mission Viejo, Dana Point and San Juan Capistrano. MNWD is a member agency of the Metropolitan water district of Southern California (MWD), a regional water wholesaler. As such, all households served by MNWD can benefit from the rebate programs offered by MWD. MNWD provided customer records for participation in rebate programs for the adoption of several indoor and outdoor technologies, household water consumption, water prices and household characteristics such as the number of residents and the size of the irrigated area. This information was then merged with data from an online survey about household adoption of a larger set of water-efficient technologies. MNWD customers received an e-mail informing them of the survey and inviting them to participate through the water agency's website. The survey was conducted during fall 2016 and consumers were asked what sort of conservation programs (water-efficient technologies and habits) they adopted (i) within the last year, (ii) between one and two years ago, and (iii) more than two years ago. The total number of respondents who completed the survey was around 4000, yielding a response rate of around $8.5 \%$. (Selection bias may occur if households equipped with water-efficient technologies are also more likely to respond to the survey. In order to investigate this potential sample selection issue, we computed adoption rates for survey respondents that participated in the rebate programs and compared them with the adoption rates reported by MNWD. Both rates were relatively close and therefore, we can assume that there is not likely a selection issue.) After removing respondent households that did not have complete customer records during the entire reference period in the survey, the resulting database is a panel of 3343 households for the period fall 2014-fall 2016.

For the first step of the analysis, that is, the estimation of the probability that a household receives a rebate for the adoption of water-efficient technologies, we consider the following four binary indicators as dependent variables:

- Rebate washers: a dummy variable that takes value 1 if a household receives a rebate for the adoption of a high-efficiency clothes washer, 0 otherwise.

- Rebate toilets: a dummy variable that takes a value 1 if a household receives a rebate for the adoption of a high-efficiency toilet. 
- Rebate landscape: a dummy variable that takes value 1 if a household participates in the landscape transformation program. This program helps households save water by removing turf and converting to a drought tolerant landscape.

- Rebate weather controller: a dummy that takes value 1 if a household receives a rebate for investing in a weather-based irrigation controllers. These controllers automatically adjust the irrigation schedule to account for changing weather.

As explanatory variables for these four regressions, we include a set of socioeconomic and demographic characteristics, indicators of each household's water conservation orientation, variables to account for each household's awareness and previous experience with rebate programs, and each household's self-reported relative importance of factors affecting the decision to adopt water conservation technologies. In terms of socioeconomic and demographic characteristics, we included variables such as the number of residents (HHS), the number of children under six years old (members $<6$ ), the number of children between six and 17 years old (members 6-17), median income in the relevant census block group (income), the proportion of people within the same census block group who have a bachelors degree (bachelors), and the median age of residents in the relevant census block group (age). Moreover, for the two regressions regarding the rebates for outdoor technologies, we also included the amount of irrigated landscape (irrigated area) and a binary indicator that accounted for households in which a gardener controls the irrigation schedule (gardener). Last, we accounted for the regression regarding the landscape transformation program a dummy variable that takes value 1 if the household belongs to a home owners association (HOA), and 0 otherwise. The reason to include this explanatory variable in this regression is that some HOAs have strict regulations about landscapes which may create difficulties or disincentives for participating in the rebate programs. The inclusion of this set of variables is consistent with [14], who estimate a probit model to analyze the determinants of receiving rebates or tax credits for the adoption of energy-saving technologies and consider both house and household characteristics as explanatory variables.

Regarding each household's water conservation orientation, we include two categorical indicators of the numbers of water-efficient indoor and outdoor technologies in the previous year (indoor technology $(t-1)$ and outdoor technology $(t-1)$ ). Similarly, [15] also consider whether households are already equipped with conservation technologies when analyzing the characteristics of energy efficiency subsidy adopters. Moreover, following [16,17], we included a water conservation habits index constructed by calculating the mean score on the survey questions related to the values of water use/conservation habits (possible answers were $1=$ yes or $0=$ no). We considered only well-established habits that have been performed for at least one year.

In order to account for household awareness and previous experience with rebate programs, we included dummy variables (rebate other washers $(t-1)$, rebate other toilets $(t-1)$, rebate other landscape $(t-1)$ and rebate other weather controller $(t-1))$ that take value 1 if a household has received a rebate in the previous period and 0 otherwise. We also included binary indicators that account for whether the head of the household is aware of the existence of the rebate program (for instance, households may receive a rebate without being aware of its existence if they are automatically presented with the discounted price at the store or if their landscapers are making the purchase decision) (rebate aware washers, rebate aware toilets, rebate aware landscape and rebate aware controller).

Last, we follow [18] and include a set of variables indicating the extent to which respondents self-report that certain incentives are relevant in the decision to adopt water-efficient technologies. In particular, we consider categorical indicators ( $0-4$ scale) for money savings in the water bill (money savings), water savings (water savings), and initial time investment (time investment), duration of the technology adoption project duration project and feedback from friends and neighbors about the technology feedback friends.

Descriptive statistics for the variables included in the propensity score matching step are provided in Table 1. 
Table 1. Summary statistics—propensity score matching.

\begin{tabular}{|c|c|c|c|c|c|}
\hline & Mean & Std. Dev. & Min & $\operatorname{Max}$ & Source \\
\hline Rebate washers & 0.024 & 0.154 & 0 & 1 & MNWD records \\
\hline Rebate toilets & 0.036 & 0.186 & 0 & 1 & MNWD records \\
\hline Rebate landscape & 0.032 & 0.175 & 0 & 1 & MNWD records \\
\hline Rebate weather controller & 0.007 & 0.086 & 0 & 1 & MNWD records \\
\hline Habits & 0.527 & 0.242 & 0 & 1 & Survey \\
\hline Rebate other washers $(t-1)$ & 0.070 & 0.255 & 0 & 1 & MNWD records \\
\hline Rebate other toilets $(t-1)$ & 0.051 & 0.219 & 0 & 1 & MNWD records \\
\hline Rebate other landscape $(t-1)$ & 0.072 & 0.258 & 0 & 1 & MNWD records \\
\hline Rebate other weather controller $(t-1)$ & 0.087 & 0.282 & 0 & 1 & MNWD records \\
\hline Rebate aware washers & 0.515 & 0.500 & 0 & 1 & Survey \\
\hline Rebate aware toilets & 0.585 & 0.493 & 0 & 1 & Survey \\
\hline Rebate aware landscape & 0.657 & 0.475 & 0. & 1 & Survey \\
\hline Rebate aware controllers & 0.342 & 0.474 & 0 & 1 & Survey \\
\hline HHS & 3.939 & 0.687 & 3 & 10 & MNWD records \\
\hline Bachelors & 0.489 & 0.109 & 0.192 & 0.723 & Census \\
\hline Income $(\$ 1000)$ & 112.792 & 33.512 & 37.161 & 198.708 & Census \\
\hline Age & 43.336 & 7.166 & 28.800 & 62.700 & Census \\
\hline Time investment & 2.238 & 1.229 & 0 & 4 & Survey \\
\hline Monetary savings & 2.696 & 1.133 & 0 & 4 & Survey \\
\hline Water savings & 2.841 & 1.075 & 0 & 4 & Survey \\
\hline Duration project & 2.071 & 1.210 & 0 & 4 & Survey \\
\hline Feedback friends & 1.736 & 1.271 & 0 & 4 & Survey \\
\hline Members $<6$ & 0.170 & 0.518 & 0 & 5 & Survey \\
\hline Members 6-17 & 0.467 & 0.875 & 0 & 9 & Survey \\
\hline Gardener & 0.510 & 0.500 & 0 & 1 & Survey \\
\hline $\mathrm{HOA}$ & 0.737 & 0.440 & 0 & 1 & Survey \\
\hline Irrigated area (1000 sq ft) & 2.811 & 3.390 & 0 & 50.163 & MNWD records \\
\hline Indoor technology $(t-1)$ & 2.151 & 1.149 & 0 & 4 & Survey \\
\hline Outdoor technology $(t-1)$ & 0.980 & 1.007 & 0 & 4 & Survey \\
\hline
\end{tabular}

For the second step, calculating ATET, we must compare the level of investment in water-efficient technologies between rebate program participants and non-participants. The usual approach in the $R \& D$ literature [8,9] was to use expenditures on new technologies as the variable of interest. However, we did not observe actual expenditures in our data. Instead, we observed only adoption decisions and rebate program participation. Therefore our investment measure was an cardinal index that accounts for the number of water-efficient technologies adopted in each period. (While this variable was a proxy for the level of investment in water-efficient technologies, it does not allow us to account for differences in technology quality that could be captured using a monetary indicator.)

To test for total crowding-out, we considered the total number of water-efficient appliances (Tot_WT), the number of indoor water-efficient appliances (Indoor_WT), and the number of outdoor water-efficient appliances (Outdoor_WT) adopted during the period of observation. To jointly test for partial crowding-out and no acceleration effect, we used NoSub_WT, IndoorNoSub_WT and OutdoorNoSub_WT. As discussed in Section 3, the difference between these variables and those used to test for total crowding-out is that we exclude the subsidized technology for the rebate program under consideration. For all of these tests, indoor water-efficient technologies include efficient clothes washers, low flow toilets, efficient dishwashers and low flow showers. Outdoor water-efficient technologies include weather-based irrigation controllers, landscape transformation, drip irrigation and pool covers. As can be seen in Table 2, there existed households in our sample that invest in the maximum number of indoor or outdoor technologies during the period of analysis, but there is not a household that invests in the maximum level of all technologies. Table 3 shows the mean and number of treatment households for each of the variables of interest. 
Table 2. Summary statistics-ATET estimation.

\begin{tabular}{lccccc}
\hline & Mean & Std. Dev. & Min & Max & N \\
\hline Tot_WT & 0.646 & 1.009 & 0 & 7 & 6686 \\
NoSub_WT & 0.546 & 0.936 & 0 & 7 & 6686 \\
Indoor_WT & 0.300 & 0.623 & 0 & 4 & 6686 \\
IndoorNoSub_WT & 0.240 & 0.573 & 0 & 4 & 6686 \\
Outdoor_WT & 0.346 & 0.706 & 0 & 4 & 6686 \\
OutdoorNoSub_WT & 0.306 & 0.657 & 0 & 4 & 6686 \\
\hline
\end{tabular}

Table 3. Summary statistics—-treatment households-ATET estimation.

\begin{tabular}{lcccccccc}
\hline & \multicolumn{2}{c}{ Rebate Washers } & \multicolumn{2}{c}{ Rebate Toilets } & \multicolumn{2}{c}{ Rebate Landscape } & \multicolumn{2}{c}{ Rebate Weather Controller } \\
\hline & Mean & N & Mean & N & Mean & N & Mean & N \\
\hline Tot_WT & 1.877 & 162 & 1.759 & 241 & 1.953 & 211 & 2.240 & 50 \\
NoSub_WT & 0.648 & 162 & 0.589 & 241 & 0.820 & 211 & 0.980 & 50 \\
Indoor_WT & 1.358 & 162 & 1.311 & 241 & 0.332 & 211 & 0.400 & 50 \\
IndoorNoSub_WT & 0.204 & 162 & 0.207 & 241 & 0.237 & 211 & 0.260 & 50 \\
Outdoor_WT & 0.519 & 162 & 0.448 & 241 & 1.621 & 211 & 1.840 & 50 \\
OutdoorNoSub_WT & 0.444 & 162 & 0.382 & 241 & 0.583 & 211 & 0.720 & 50 \\
\hline
\end{tabular}

\section{Results and Policy Implications}

\subsection{The Probability of Participating in a Rebate Program}

As explained in Section 3, we started our analysis by estimating the probability of receiving a rebate. In Table 4 we report the probit estimation results for each of the rebate programs considered. The estimations reported in columns (1) and (2) are for indoor water-efficient technologies, i.e., rebate washers and rebate toilets, whereas columns (3) and (4) show the results for the outdoor water-efficient technologies, that is, rebate landscape and rebate weather controller.

In general, the estimated coefficients, when significant, were intuitive in the four models. Here, we review some of the most noteworthy results. (Given the large number of explanatory variables included in the first step, we have computed the variance inflated factor (VIF) and tolerance value to test for multicollinearity, and we reject it in all cases.) Comparing the four estimations, we observe, as could be expected, that awareness of each rebate was positive and significant at the $1 \%$ level in the four models. That is, this variable was one of the main determinants of rebate participation across different programs. However, previous experience with rebate programs did not have a significant effect in any of the estimations.

Regarding socioeconomic and demographic characteristics, HHS had a positive and significant effect (at 5\%) on participation in the rebate program for efficient washers and for landscape transformation. That is, the more people living in the household, and presumably more frequent laundry loads, the higher the probability of participating in the rebate program. Income has a positive and significant effect (although only at 10\%) on rebate landscape, as landscape transformation projects can be expensive even with a rebate. Age also had a positive effect on rebate landscape at $1 \%$, whereas the effect was negative and significant on rebate weather controller at $10 \%$. This would be consistent with a desire to save water but aversion to perceived "high-tech" solutions. Moreover, the coefficient of members $<6$ was positive and significant at $5 \%$ in the 4 th estimation. This indicates that households with a higher proportion of kids under six had a higher probability of receiving a rebate for the adoption of weather-based irrigation controllers, which was a technology that allows them to maintain but efficiently irrigate their lawn. 
Table 4. Estimation results for the probability of receiving a rebate.

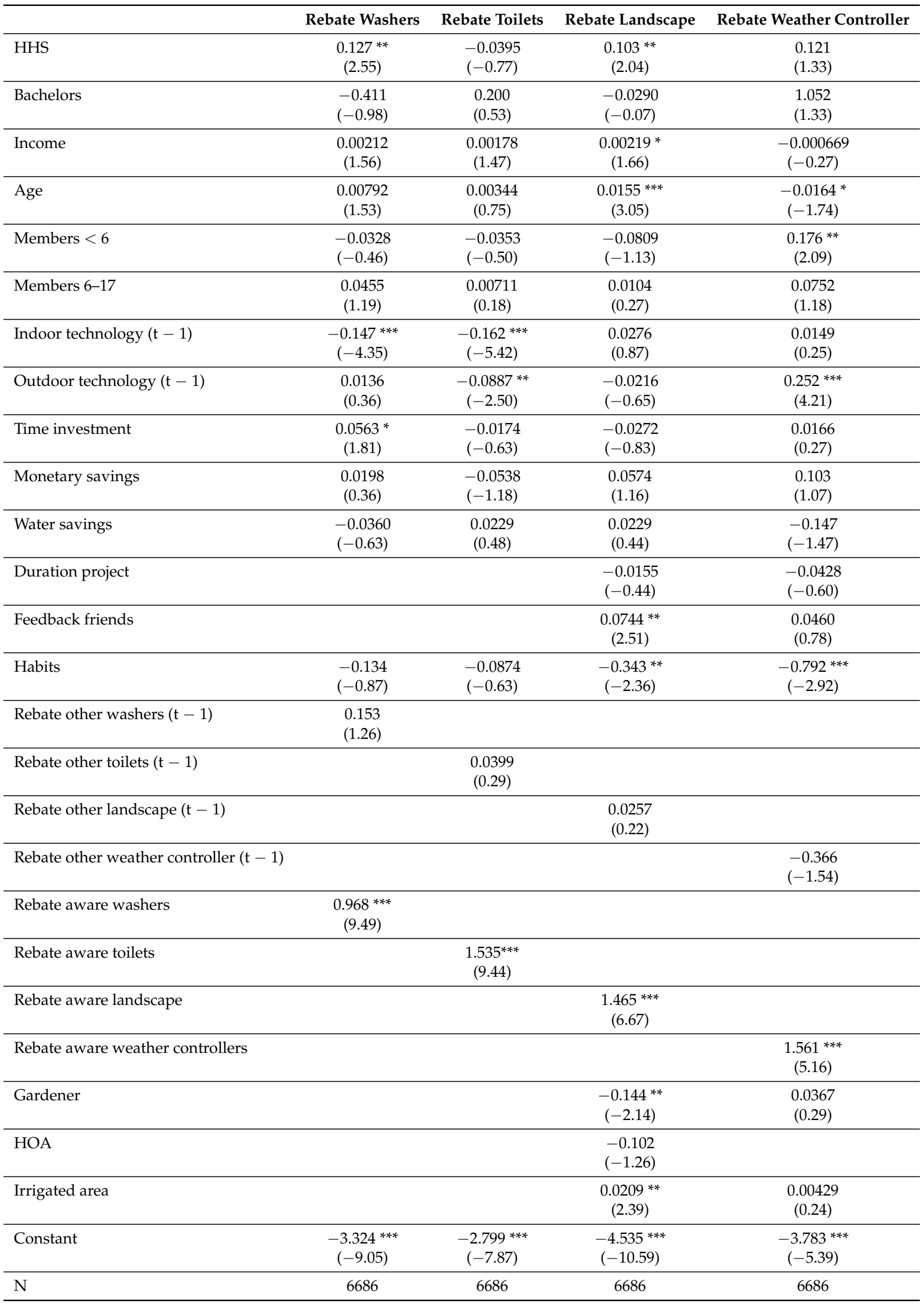

$t$ statistics in parentheses. ${ }^{*}(p<0.10),{ }^{* *}(p<0.05),{ }^{* * *}(p<0.01)$. 
In terms of the effects of a household's water conservation orientation, we find that households that have previously adopted indoor water-efficient technologies were less likely to participate in indoor rebate programs (the estimated coefficients are significant at the $1 \%$ level). For the case of previous outdoor technologies, this effect is also negative and significant at $5 \%$ for rebate toilets, but it was positive and significant at $1 \%$ for rebate weather controller. The negative effect could mean that these households do not need the support of the rebate program to adopt more water-efficient technologies. Alternatively, households that have already installed water-efficient technologies may be less likely to further invest in new ones-perhaps feeling that they already have achieved adequate efficiency gains. Regarding the positive effect, one possible explanation is that previous satisfactory experience in conserving water may encourage households to participate in the rebate for weather-based irrigation controllers. The coefficient for habits was negative and significant for the outdoor technology estimations, at the $5 \%$ and $1 \%$ levels for rebate landscape and rebate weather controller, respectively. Similar to the negative effect of previous technologies on rebate participation, households manifesting water conservation habits may be more likely to invest in these technologies without receiving a rebate, but habits may also be perceived as a substitute for efficient technologies.

Time investment has a positive and significant effect at the $10 \%$ level on rebate washers, i.e., households that attached greater importance to the amount of time required to participate in a rebate program were more likely to receive a rebate for efficient washers. Moreover, feedback friends had a positive and significant effect at $5 \%$ on rebate landscape, indicating that feedback from friends who have previously transformed their landscape increased the probability of receiving this rebate.

Last, regarding the variables directly linked to the outdoor characteristics, we found that gardener had a negative and significant effect at $5 \%$ on rebate landscape, whereas the size of the irrigated area had a positive and significant effect at $5 \%$ on this probability. However, neither of these characteristics had a significant effect on rebate weather controller.

\subsection{Hypothesis Testing}

As explained in Section 3, we used the propensity scores obtained in the first stage as matching arguments for the second stage. Table 5 reports the second stage estimated average treatment effect on the treated for the variables of interest summarized in Table 2. These estimates represent the average additional numbers of total (Tot_WT and NoSub_WT), indoor(indoor_WT and IndoorNoSub_WT) and outdoor (outdoor_WT and OutdoorNoSub_WT) water-efficient technologies adopted by households participating in rebate programs.

First, we considered Hypothesis 1, i.e., total crowding-out. Our results showed that $\tau^{A T E T}$ in column (1) was positive and significant for each of the four rebates considered. This indicates that all the rebate programs in the analysis generated higher investments in water-efficient technologies, on average, so we can reject Hypothesis 1: total crowding-out. This result remained true when we distinguished between indoor and outdoor water-efficient technologies, as both average treatment effects on the treated for indoor_WT and outdoor_WT, in columns (3) and (5) respectively, are positive and significant for the four rebates.

However, when we tested Hypothesis 2: partial crowding out, and Hypothesis 3: no acceleration, we found mixed results. For indoor rebates, the average treatment effect on the treated for NoSub_WT, in column (2), was negative but not statistically significant. Thus, we rejected Hypothesis 2 but we cannot reject Hypothesis 3, i.e., we do not find evidence of partial crowding-out or acceleration. That is, the total number of water-efficient technologies adopted, excluding the technology that was subsidized, was neither higher nor lower for participant households compared to non-participant households. In the case of rebates for outdoor water-efficient technologies, $\alpha^{A T E T}$ is positive, but significant only for rebate weather controller when using NoSub_WT, in column (2), as variable of interest, i.e., we find evidence of acceleration.

When we looked at the disaggregated indicators for testing partial crowding-out and no acceleration effect we find a significant negative $\alpha^{A T E T}$ when considering IndoorNoSub_WT, shown 
in column (4). Thus, we cannot reject partial crowding-out or no acceleration for households receiving rebates for indoor water-efficient technologies. This seems to indicate that while, on average, households participating in rebate programs for the adoption of indoor technologies also invested more in outdoor technologies than the control group, their total level of water-efficient technologies adopted during the year excluding the subsidized technology was not significantly higher. However, $\alpha^{A T E T}$ was positive and significant for both outdoor rebates when we use OutdoorNoSub_WT, in column (6), indicating that we rejected both Hypotheses 2 and 3. That is, households receiving a rebate for landscape transformation or for the investment in weather-based irrigation controllers were more likely to invest in other outdoor water-efficient technologies. These rebates were not only promoting investment in the subsidized technology, but also in other outdoor technologies.

Table 5. Average treatment effects.

\begin{tabular}{|c|c|c|c|c|c|c|}
\hline & $\begin{array}{c}(1) \\
\text { Tot_WT } \\
\tau^{A T E T}\end{array}$ & $\begin{array}{c}\text { (2) } \\
\text { NoSub_WT } \\
\alpha^{A T E T}\end{array}$ & $\begin{array}{c}\text { (3) } \\
\text { Indoor-WT } \\
\tau^{A T E T}\end{array}$ & $\begin{array}{c}(4) \\
\alpha^{A T E T} \\
\text { IndoorNoSub_WT }\end{array}$ & $\begin{array}{c}\text { (5) } \\
\text { Outdoor_WT } \\
\tau^{A T E T} \\
\end{array}$ & $\begin{array}{c}\text { (6) } \\
\text { OutdoorNoSub_WT } \\
\alpha^{A T E T}\end{array}$ \\
\hline Rebate washers & $\begin{array}{c}1.068^{* * *} \\
(8.97)\end{array}$ & $\begin{array}{l}-0.105 \\
(-0.96)\end{array}$ & $\begin{array}{c}0.914^{* * * *} \\
(13.09)\end{array}$ & $\begin{array}{c}-0.216^{* * *} \\
(-3.26)\end{array}$ & & \\
\hline Rebate toilets & $\begin{array}{l}0.971^{* * *} \\
(9.06)\end{array}$ & $\begin{array}{l}-0.129 \\
(-1.30)\end{array}$ & $\begin{array}{l}0.921 * * * \\
(15.10)\end{array}$ & $\begin{array}{c}-0.154^{* * * *} \\
(-2.78)\end{array}$ & & \\
\hline Rebate landscape & $\begin{array}{c}1.194^{* * *} \\
(10.31)\end{array}$ & $\begin{array}{l}0.171 \\
(1.58)\end{array}$ & & & $\begin{array}{l}1.232^{* * *} \\
(15.81)\end{array}$ & $\begin{array}{l}0.194^{* *} \\
(2.52)\end{array}$ \\
\hline $\begin{array}{l}\text { Rebate weather } \\
\text { controller }\end{array}$ & $\begin{array}{c}1.520 * * * \\
(9.70)\end{array}$ & $\begin{array}{l}0.420 * * \\
(2.09)\end{array}$ & & & $\begin{array}{c}1.480 \text { *** } \\
(12.07)\end{array}$ & $\begin{array}{l}0.420 * * * \\
(3.14)\end{array}$ \\
\hline
\end{tabular}

\subsection{Policy Implications}

Our results indicated that rebate programs may have different effects on the level of investment in water-efficient technologies depending on the type of subsidized technology considered. One possible explanation for the differences in rebate effects for indoor and outdoor technologies may be that the subsidized technologies are at different stages of the adoption process. Table 6 shows the percentage of households in our sample that have adopted each technology just prior to our period of analysis. We observed that efficient washers and low flow toilets had already been adopted by around $58 \%$ and $61 \%$ of our sample, respectively; whereas landscape transformation and weather-based controllers had already been adopted by only $27.07 \%$ and $14.92 \%$, respectively.

Table 6. Rates of water-efficient technology adoption prior to the analysis (\% of the sample).

\begin{tabular}{lc}
\hline & Adoption Rates Prior to the Analysis \\
\hline Efficient washers & $58.42 \%$ \\
Low flow toilets & $61.29 \%$ \\
Landscape transformation & $27.07 \%$ \\
Weather-based controllers & $14.92 \%$ \\
\hline
\end{tabular}

Following [19], households adopting a technology after 50\% of the population already has adopted, as is the case for our indoor technology adopters, can be categorized as late majority. According to this seminal work, this type of consumer was characterized by being skeptical about innovation, having little opinion leadership, and being in contact with other consumers in late majority and early majority. This characterization seemed consistent with our findings that these consumers adopt the subsidized technology but do not experience an acceleration effect. Regarding the outdoor water-efficient technologies, households performing landscape transformation and adopting weather-based controllers in our study can be categorized as early majority and early adopters. These consumers had the highest degree of opinion leadership among the other adopter categories and therefore are more likely to adopt other water-efficient technologies. Again, this was consistent with 
our findings that households receiving rebates for the adoption of outdoor technologies tend to invest significantly more in other technologies. All of this suggests that rebate programs to promote the adoption of water-efficient technologies may be more effective when the level of adoption is still low, such as for our outdoor technologies, instead of promoting more well-established indoor technologies.

As noted in Section 1, our dataset did not allow us to directly estimate the amount of water conservation achieved due to the rebate programs because we lack exact adoption dates. Thus, it was not possible to conduct benefit-cost or cost-effectiveness analyses for the rebate programs using only this data. In order to address this issue, we combine our results with the water conservation estimates from the water short list by [20] to draw policy conclusions. Because we rejected for all rebate programs the null hypotheses of total and partial crowding-out (when considering Tot_WT and NoSub_WT), we can say that the four programs generate additional water savings. According to [20], indoor technologies tend to achieve lower water savings compared to outdoor technologies. In particular, efficient washers and low flow toilets may reduce indoor water use by around $17 \%$ and $19 \%$, respectively, whereas estimated outdoor water savings for landscape transformation and weather-based controllers are $20-100 \%$ (water savings achieved by replacing turf grass with water-wise landscaping differs based on the proportion of lawn replaced) and $30 \%$, respectively. Considering that average indoor and outdoor water use by Californian households were roughly the same, it was apparent that outdoor technologies are likely to generate larger water savings. Moreover, as seen above, rebates for outdoor technologies not only generated a direct additionality effect, but also an acceleration effect. Therefore, for both of these reasons, it seemed that outdoor rebate programs have greater potential water savings than indoor programs. To investigate relative cost-effectiveness for water agencies (In order to analyze cost-effectiveness for consumers, one would need to compute the level of water savings due to the rebate programs, but also the percentage of the investment covered by the rebate program. Unfortunately, that information was not available in our data. Participant households received the rebate after purchasing a qualifying device. There was a large number of qualifying devices available from a large number of vendors for each of the technologies considered in this analysis, and therefore, the percentage of the cost covered varies depending on the device selected by the household and the store where it is purchased. MNWD did not ask customers to report their purchase cost and therefore this data is not available), we show in Table 7 the rebate amounts for each of the technologies considered. The amounts are relatively similar, with efficient washers being the highest. Therefore, if households appropriately used each technology and achieve the estimated savings mentioned above, one could expect that rebates for outdoor technologies would also be the most cost-effective. However, further analysis would be needed to investigate these speculative claims.

Table 7. Rebate amount perceived by participant.

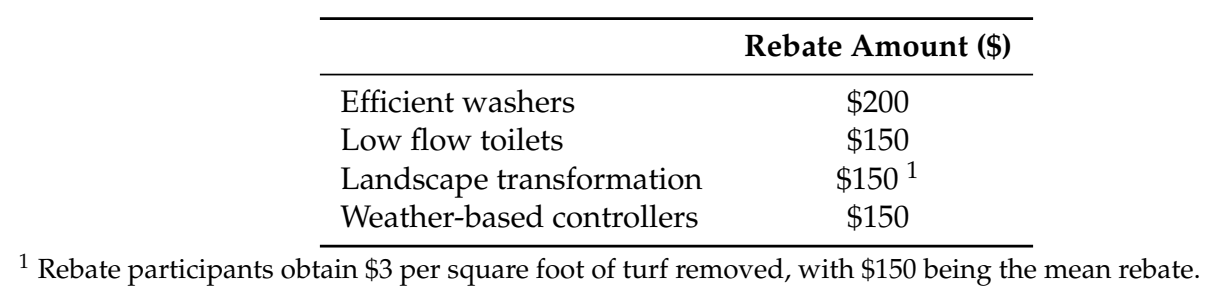

\section{Conclusions}

This paper analyzes the effects of several residential rebate programs on the adoption of indoor and outdoor water-efficient technologies in a Southern California water district. To do so, we adapt a common approach in the R\&D literature that allows us to address two research questions. First, we test whether each rebate program generates larger investment in water-efficient technologies that would not have occurred in the absence of the rebate. Second, we analyze whether each rebate program promotes additional private investments in the other technologies we observe. 
Our results indicate that while rebates for indoor technologies increase adoption to levels that would not have occurred in the absence of the program, these rebates do not generate an acceleration effect. In the case of rebates for outdoor technologies, we observe both effects, although the acceleration effect is limited to additional private investment in outdoor technologies. That is, the impact of rebates for outdoor technologies seems to be greater. Furthermore, because the outdoor water-efficient technologies in our analysis are in early stages of adoption, rebates would be useful to further promote the diffusion of these technologies into additional households.

Moreover, while our database does not allow us to estimate the actual level of water savings caused by the rebate programs, we can use the water short list by [20] to conclude that rebates for the adoption of outdoor water-efficient technologies seem to generate larger direct water savings, and also indirect water savings due to the acceleration effect. Moreover, considering that the rebate amounts are almost identical across subsidized technologies, one could expect the rebates for outdoor technologies to be more cost-effective if households use them appropriately. However, additional research that directly analyzes the cost-effectiveness of rebate programs is needed to substantiate these claims. In the current context of increasing water scarcity and heightened budget austerity, such information could help policy makers design rebate programs that generate larger benefits on limited budgets.

Author Contributions: The paper was written with the contributions of all co-authors. Conceptualization, M.P.U.; methodology, M.P.U.; formal analysis, M.P.U.; writing- original editing, M.P.U.; writing- review and editing, K.A.B.; project management, K.A.B.; funding acquisition, K.A.B. All authors have read and approved the submission.

Funding: This material is based upon work that is supported by the National Institute of Food and Agriculture, U.S. Department of Agriculture, Hatch project CA-R-ENS-5087-H.

Acknowledgments: The authors thank the Moulton Niguel Water District for funding and facilitating the collection of household survey data and providing access to monthly billing records. Any remaining errors are the authors' responsibility.

Conflicts of Interest: The authors declare no conflict of interest.

\section{References}

1. OECD. OECD Statistics. 2017. Available online: https://www.oecd-ilibrary.org/economics/data/oecdstat_data-00285-en (accessed on 30 October 2018).

2. Jaffe, A.B.; Stavins, R.N. Dynamic Incentives of Environmental Regulations: The Effects of Alternative Policy Instruments on Technology Diffusion. J. Environ. Econ. Manag. 1995, 29, S43-S63. [CrossRef]

3. Jaffe, A.B.; Newell, R.G.; Stavins, R.N. A tale of two market failures: Technology and environmental policy. Ecol. Econ. 2005, 54, 164-174. [CrossRef]

4. Joskow, P.L.; Marron, D.B. What Does a Negawatt Really Cost? Evidence from Utility Conservation Programs. Energy J. 1992, 13, 41-74. [CrossRef]

5. Boomhower, J.; Davis, L.W. A credible approach for measuring inframarginal participation in energy efficiency programs. J. Public Econ. 2014, 113, 67-79. [CrossRef]

6. Bennear, L.S.; Lee, J.M.; Taylor, L.O. Municipal Rebate Programs for Environmental Retrofits: An Evaluation of Additionality and Cost-Effectiveness. J. Policy Anal. Manag. 2013, 32, 350-372. [CrossRef]

7. Brent, D.A.; Cook, J.H.; Olsen, S. Social Comparisons, Household Water Use, and Participation in Utility Conservation Programs: Evidence from Three Randomized Trials. J. Assoc. Environ. Resour. Econ. 2015, 2, 597-627. [CrossRef]

8. Czarnitzki, D.; Hussinger, K. The Link between RED Subsidies, RED Spending and Technological Performance; ZEW Discussion Paper; ZEW Centre for European Economic Research: Mannheim, Germany, 2004; Volume 4, doi:10.2139/ssrn.575362.

9. Freitas, I.B.; Castellacci, F.; Fontana, R.; Malerba, F.; Vezzulli, A. Sectors and the additionality effects of R\&D tax credits: A cross-country microeconometric analysis. Res. Policy 2017, 46, 57-72. [CrossRef]

10. Caliendo, M.; Kopeinig, S. Some practical guidance for the implementation of propensity score matchning. J. Econ. Surv. 2008, 22, 31-72. [CrossRef]

11. Dehejia, R.H.; Wahba, S. Propensity Score-Matching Methods for Nonexperimental Causal Studies. Rev. Econ. Stat. 2002, 84, 151-161. [CrossRef] 
12. Becker, S.; Ichino, A. Estimation of average treatment effects based on propensity scores. Stata J. 2002, 2, 358-377. [CrossRef]

13. Austin, P.C. Statistical Criteria for Selecting the Optimal Number of Untreated Subjects Matched to Each Treated Subject When Using Many-to-One Matching on the Propensity Score. Am. J. Epidemiol. 2010, 172, 1092-1097. [CrossRef] [PubMed]

14. Alberini, A.; Gans, W.; Towe, C. Free Riding, Upsizing, and Energy Efficiency Incentives in Maryland Homes; Technical Report; Fondazione Eni Enrico Mattei (FEEM): Milan, Italy, 2013.

15. Allcott, H.; Knittel, C.; Taubinsky, D. Tagging and Targeting of Energy Efficiency Subsidies. Am. Econ. Rev. 2015, 105, 187-91. [CrossRef]

16. Beaumais, O.; Briand, A.; Millock, K.; Nauges, C. What Are Households Willing to Pay for Better Tap Water Quality? A Cross-Country Valuation Study; Université Paris 1 Panthéon-Sorbonne (Post-Print and Working Papers); HAL: Paris, France, 2010.

17. Pérez-Urdiales, M.; García-Valiñas, M.Á. Efficient water-using technologies and habits: A disaggregated analysis in the water sector. Ecol. Econ. 2016, 128, 117-129. [CrossRef]

18. Tonn, B.; Berry, L. Determinants of participation in home energy audit/loan programs: Discrete choice model results. Energy 1986, 11, 785-795. [CrossRef]

19. Rogers, E. Diffusion of Innovations, 4th ed.; Collier Macmillan: New York, NY, USA, 2003.

20. Inskeep, B.D.; Attari, S.Z. The Water Short List: The Most Effective Actions U.S. Households Can Take to Curb Water Use. Environ. Sci. Policy Sustain. Dev. 2014, 56, 4-15. [CrossRef]

(C) 2019 by the authors. Licensee MDPI, Basel, Switzerland. This article is an open access article distributed under the terms and conditions of the Creative Commons Attribution (CC BY) license (http://creativecommons.org/licenses/by/4.0/). 